\title{
Introduction: Why Facts Matter
}

\section{The Need for Information}

The changeable nature of human knowledge about the world's facts has been recognized since classical antiquity. ${ }^{1}$ The history of science and of inquiry in all its forms clearly shows that facts, theories, concepts, and methods are not endowed with a fixed permanence, but reflect an ever-changing cognitive state of the art with variation in time, place, and cultural modus operandi. Science is not an object of some sort, a thing-like "body of knowledge"-it is an activity, a dynamic cognitive enterprise geared to the creation and active manipulation of information. Human cognition is a process that actively develops and with this development we not only have change but also the emergence of a novelty that radically divides the present from what has gone before. Our cognitive endeavors are involved in a constant process of transformation. Since the rise of science, no two human generations have viewed the world and its contents in just the same way. Science, properly understood, is not a body of theories, but a process-an ongoing project of inquiry whose products are ever changing.

The development of knowledge-and of science in particular-is thus a human activity which, like any other, involves the expenditure of time, effort, and other resources-and accordingly has an ineliminable economic dimension. Knowledge possesses an ineliminable economic dimension because of its nature as an activity which, as such, has a substantial involvement with costs and benefits. Virtually every aspect of the way we acquire, maintain, and use our knowledge can be properly understood and explained only from an economic point of view. Throughout the entire range of our endeavors in this world, we are involved in the expenditure of limited resources, and knowledge is no exception to this rule. Its acquisition, processing, storage, retrieval, and utilization are activities which, like any other human endeavor, engender costs. Over and above this practical dimension there are also certain purely cognitive disabilities and negativities-that is, costs-involved in the lack of knowledge, in ignorance, error, and confusion. And on the positive side, it has come to be increasingly apparent in recent years that knowledge is cognitive capital, and that its extraction and consolidation involves the creation of intellectual assets, in which both produc-

1 Veniet tempus quo posteri nostri tam aperta nos nescisse mirentur: "There will come a time when our descendants will be amazed that we did not know things that are so plain to them.” (Seneca, Natural Questions, vol. 2: Books 4-7, Cambridge, MA: Harvard University Press, 1972, VII, 25, 5.) 
ers and users have a very real interest. Any theory of knowledge that ignores this economic aspect of the matter does so to the detriment of its own adequacy.

That greatest of American philosophers Charles Sanders Peirce (1839-1914) proposed to construe the "economy of research" at issue in knowledge development in terms of the sort of balance of assets and liabilities that we today would call cost-benefit analysis. ${ }^{2}$ Peirce insisted that one must recognize the inevitably economic nature of any human enterprise-inquiry included:

The value of knowledge is, for the purpose of science, in one sense absolute. It is not to be measured, it may be said, in money; in one sense that is true. But knowledge that leads to other knowledge is more valuable in proportion to the trouble it saves in the way of expenditure to get that other knowledge. Having a certain fund of energy, time, money, etc., all of which are merchantable articles to spend upon research, the question is how much is to be allowed to each investigation; and the value of that investigation is how much it will pay for us to spend upon it. Relatively, therefore, knowledge, even of a purely scientific kind, has a money value. ${ }^{3}$

On the side of benefits of scientific claims, Peirce also recognized a wide variety of epistemic factors: closeness of fit to data, explanatory value, novelty, simplicity, accuracy of detail, precision, parsimony, concordance with other accepted theories, even antecedent likelihood and intuitive appeal. And he placed in the liability column those cost-geared factors of "the dismal science": the expenditure of time, effort, energy, and money needed to secure and substantiate our claims. And this view of the matter is entirely appropriate, although the introduction of such an economic perspective does not, of course, detract from the value of the quest for knowledge as an intrinsically worthy venture endowed with a perfectly valid l'art pour l'art aspect.

Philosophical epistemologists subsequent to Peirce have paid regrettably little attention to these matters. ${ }^{4}$ Indeed, they often proceed on the tacit assumption that information is something that is economically costless-a free good that comes to rational inquirers without expenditure and effort. But even casual consideration shows that such a view is totally erroneous and unrealistic.

2 On Peirce's project on economy of research, see the author's Peirce's Philosophy of Science (Notre Dame and London: Notre Dame Press, 1976), as well as Cornelius F. Delaney, "Peirce on 'Simplicity' and the Conditions of the Possibility of Science," in: Linus J. Thro (ed.), History of Philosophy in the Making (Washington, D.C.: University Press of America, 1982), pp. 177-194. 3 Charles Sanders Peirce, Collected Papers, ed. by Charles Hartshorne and Paul Weiss, vol. 1 (Cambridge, MA: Harvard University Press, 1931), sect. 1.122 [c. 1896].

4 One valuable contribution in this area is Fritz Machlup, The Production and Distribution of Knowledge in the United States (Princeton: Princeton University Press, 1962). 
For sure, knowledge brings great benefits. The relief of ignorance is foremost among them. Man has evolved within nature into the ecological niche of an intelligent being. In consequence, the need for understanding, for "knowing one's way about," is one of the most fundamental demands of the human condition. Man is Homo quaerens. The need for knowledge is part and parcel of our nature. A deep-rooted demand for information and understanding presses in upon us, and we have little choice but to satisfy it. Once the ball is set rolling it keeps on under its own momentum-far beyond the limits of strictly practical necessity. The great Norwegian polar explorer Fridtjof Nansen put it well. What drives men to the polar regions, he said, is:

... the power of the unknown over the human spirit. As ideas have cleared with the ages, so has this power extended its might, and driven Man willy-nilly onwards along the path of progress. It drives us in to Nature's hidden powers and secrets, down to the immeasurably little world of the microscopic, and out into the unprobed expanses of the Universe... it gives us no peace until we know this planet on which we live, from the greatest depth of the ocean to the highest layers of the atmosphere. This Power runs like a strand through the whole history of polar exploration. In spite of all declarations of possible profit in one way or another, it was that which, in our hearts, has always driven us back there again, despite all setbacks and suffering. ${ }^{5}$

The discomfort of unknowing is a natural component of human sensibility. To be ignorant of what goes on about us is almost physically painful for us-no doubt because it is so dangerous from an evolutionary point of view. It is a situational imperative for us humans to acquire information about the world. We have questions and we need answers. Homo sapiens is a creature who must, by his very nature, feel cognitively at home in the world. The requirement for information, for cognitive orientation within our environment, is as pressing a human need as that for food itself. We are rational animals and must feed our minds even as we must feed our bodies. Relief from ignorance, puzzlement, and cognitive dissonance is one of cognition's most important benefits. These benefits are both positive (pleasures of understanding) and negative (reducing intellectual discomfort through the removal of unknowing and ignorance and the diminution of cognitive dissonance). The basic human urge to make sense of things is a characteristic aspect of our make-up-we cannot live a satisfactory life in an environment we do not understand. For us intelligent creatures, cognitive orientation is itself a practical need: cognitive disorientation is physically stressful and distressing. As William James observed: "It is of the utmost practical importance

5 Fridtjof Nansen as quoted in Roland Huntford, The Last Place on Earth (New York, 1985), p. 200. 
to an animal that he should have prevision of the qualities of the objects that surround him."6

\section{Cognition as an Economic}

The benefits of knowledge are twofold: theoretical (or purely cognitive) and practical (or applied). The theoretical/cognitive benefits of knowledge relate to its satisfactions in and for itself, for understanding is an end unto itself and, as such, is the bearer of important and substantial benefits-benefits which are purely cognitive, relating to the informativeness of knowledge as such. The practical benefits of knowledge, on the other hand, relate to its role in guiding the processes by which we satisfy our (noncognitive) needs and wants. The satisfaction of our needs for food, shelter, protection against the elements, and security against natural and human hazards all require information. And the satisfaction of mere desiderata comes into it as well. We can, do, and must put knowledge to work to facilitate the attainment of our goals, guiding our actions and activities in this world into productive and rewarding lines. And this is where the practical payoff of knowledge comes into play.

The costs (and benefits) of knowledge acquisition will, of course, vary with people's conditions and circumstances. Time is of the essence here. The medical knowledge of the twentieth century was not available to patients in the eighteenth century-"not for all the tea in China." In pursuing information, as in pursuing food, we have to settle for the best we can obtain at the time. We have questions and need answers-the best answers we can get here and now, regardless of their imperfections. We cannot wait until all returns are in. Our needs and wants impel us to resolve our questions by means of the best available answers we can get. What matters for us is not ideal and certain knowledge in the light of complete and perfect information, but getting the best estimate that is actually obtainable here and now.

The impetus to inquiry-to investigation, research, and acquisition of information about the world we live in-can accordingly be validated in strictly economic terms with a view to potential costs and benefits of both theoretical and practical sorts. We humans need to achieve both an intellectual and a physical accommodation to our environment.

6 William James, “The Sentiment of Rationality," in: The Will to Believe and Other Essays in Popular Philosophy (New York and London: Putnam, 1897), pp. 62-88 [see pp. 78-79]. 
The Ancients saw man as the rational animal (zoõn logon echõn), set apart from other creatures by capacities for speech and deliberation. Under the precedent of Greek philosophy, Western thinkers have generally deemed the use of thought for the guidance of our actions to be at once the glory and the duty of Homo sapiens.

To behave rationally is to make use of one's intelligence to figure out the best thing to do in the circumstances. Rationality is a matter of the intelligent pursuit of appropriate objectives; it consists in the use of reason to resolve choices in the best feasible way. Above all, it calls for the intelligent pursuit of appropriate ends, for the effective and efficient cultivation of appropriately appreciated benefits. Rationality requires doing the best one can with the means at one's disposal, striving for the best results that one can expect to achieve within the range of one's resources, specifically including one's intellectual resources. Be it in matters of belief, action, or evaluation, its mission centers about the deliberate endeavor to secure an optimally favorable balance of benefits relative to expenditure.

Accordingly, rationality has an ineliminable economic dimension. The optimal use of resources is, after all, a crucial aspect of rationality. It is against reason to expend more resources on the realization of a given end than one needs to. ${ }^{7}$ And it is against reason to expend more resources on the pursuit of a goal than it is worth-to do things in a more complex, inefficient, or ineffective way than is necessary in the circumstances. But it is also against reason to expend fewer resources in the pursuit of a goal than it is worth, unless these resources can be used to even better effect elsewhere. Cost effectiveness-the proper coordination of costs and benefits in the pursuit of our ends-is an indispensable requisite of rationality.

Economy of effort is a cardinal principle of rationality that helps to explain many aspects of the way in which we transact our cognitive business. Why are encyclopedias organized alphabetically rather than topically? Because this simplifies the search process. Why are accounts of people's doings or a nation's transactions standardly presented historically, with biographies and histories presented in chronological order? Because an account that moves from causes to effect simplifies understanding. Why do libraries group books together by topic and language rather than, say, alphabetically by author? Because this minimizes the difficulties of search and access. We are in a better position to under-

7 But is it indeed irrational to give a gift more costly than the social situation requires? By no means! It all depends on one's aims and ends, which may, on such an occasion, lie in a desire to cause the recipient surprise and pleasure, rather than merely doing the customary thing. There is an important difference between wastefulness and generosity. 
stand innumerable features of the way in which people conduct their cognitive business once we take the economic aspect into account.

It is particularly noteworthy from such an economic point of view that there will be some conditions and circumstances in which the cost of acquiring information-even assuming that it is to be had at all in the prevailing state of the cognitive art-is simply too high relative to its value. There are (and are bound to be) circumstances in which the acquisition costs of information exceed the benefits or returns on its possession. In this regard, too, information is just like any other commodity. The price is sometimes more than we can afford and often greater than any conceivable benefit that would ensue. (This is why people generally do not count the number of hairs in their eyebrows.)

Rationality and economy are thus inextricably interconnected. Rational inquiry is a matter of epistemic optimizations, of achieving the best overall balance of cognitive benefits relative to cognitive costs. Cost-benefit calculation is the crux of the economy of effort at issue. The principle of least effort-construed in a duly intellectualized manner-is bound to be a salient feature of cognitive rationality. ${ }^{8}$ A version of Occam's Razor obtains throughout the sphere of cognitive rationality: complicationes non multiplicandae sunt praeter necessitatem. Efforts to secure and enlarge knowledge are worthwhile only insofar as they are cost effective in that the resources we expend for these purposes are more than compensated for through benefits obtained-as is indeed very generally the case. But not always. We are, after all, finite beings who have only limited time and energy at our disposal. And even the development of knowledge, important though it is, is nevertheless of limited value-it is not worth the expenditure of every minute of every day at our disposal.

The standard economic process of cost-effectiveness tropism is operative throughout the cognitive domain. Rational inquiry is rigorously subject to the economic impetus to securing maximal product for minimal expenditure. Concern for answering our questions in the most straightforward, most cost-effective way is a crucial aspect of cognitive rationality in its economic dimension.

The long and short of it is that knowledge acquisition is a purposive human activity-like most of our endeavors. And as such it involves the ongoing expenditure of resources for the realization of the objectives-description, explanation, prediction, and control-that represent the defining characteristics of our cogni-

8 On this theme, see the important investigations of George K. Zipf, Human Behavior and the Principle of Least Effort (Cambridge, MA: Addison-Wesley, 1949). Zipf's investigations furnish a wide variety of interesting examples of how various aspects of our cognitive proceedings exemplify a tendency to minimize the expenditure of energy. 
tive endeavors. The balance of costs and benefits becomes critical here, and endows the cognitive enterprise with an unavoidably economic aspect. ${ }^{9}$

\section{Wider Vistas}

Some creatures survive and thrive in the world by means of speed that enables them to outrun their enemies. Some have hard shells that render them unreachable. Some are so prolific that their predators cannot avert the survival of another generation. But the survival instrumentality of our species is in fact intelligence. We humans survive and thrive by figuring out how best to go about it. We exploit information for the guidance of action.

In order to do this, however, we need to secure or at least approximate the facts. For us, access to the facts is as important as food-indeed arguably more so since we could not survive the latter save by means of the former.

Accordingly, the following considerations are critical in addressing the question of why facts matter:

1. We humans must make our way in the world on a basis of our beliefs regarding the prevailing facts.

2. For the most part we are reactive rather than productive in relation to facts: we are for the most part situationally required to adjust to facts whose nature is outside the range of our creative control.

3. We can accommodate our proceedings to the facts only by learning about them. An appropriate understanding of relevant fact is indispensable for the efficacy of our effects and indeed for our very survival.

All in all, achieving an adequate knowledge of relevant fact is an indispensable instrumentality for us. The facts matter because we cannot survive without adequate access to them.

9 On this theme, see also the author's Cognitive Economy (Pittsburgh: University of Pittsburgh Press, 1989). 